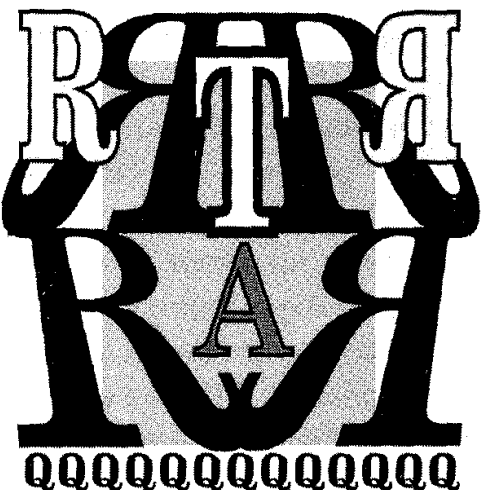

\title{
Autobiografía poética de Antonio Machado
}

\author{
María ANDUEZA
}

$\mathbf{L}$

eer la poesía de Antonio Machado es conocer su vida; esencial poeta lírico, Machado entrega junto con sus poemas su Autobiografia. De inmediato y con precisión un lector atento puede establecer la íntima relación entre la vida y la obra machadiana. Si la vida se refleja en la obra, la obra es clara manifestación de la vida. Ambas se interpenetran, se complementan y se iluminan mutuamente. El poeta canta el lugar de su nacimiento; al padre, al amigo, al amor, al tiempo y al espacio geográfico, temas recurrentes en la poesía de Antonio Machado que él supo transformar en símbolos perdurables. Si el gran poeta que fue Antonio Machado parece opacar al gran hombre que también lo fue, son los hechos de su vida personal los que crearon su poesía. En el Prólogo a Soledades, Machado habla de la poesía como respuesta del alma al "contacto del mundo":

Pensaba yo que el elemento poético no era la palabra por su valor fónico, ni el color, ni la línea, ni un complejo de sensaciones, sino una honda palpitación del espíritu: lo que pone al alma, si es que algo pone, o lo que dice, si es que algo dice, con voz propia, en respuesta al contacto del mundo. ${ }^{1}$

A ese contacto, Machado dará su respuesta poética. Gracias a los versos machadianos hoy podemos reconstruir con facilidad la autobiografia poética de Antonio Machado que él escribió a lo largo de su vida y de su tiempo.

INFANCIA: SEVILLA, 1875-1883

En el Prólogo de Campos de Castilla, Machado afirmó que la "misión del poeta es inventar nuevos poemas de lo eterno humano, historias animadas que, siendo 
suyas, viviesen, no obstante, por sí mismas". ${ }^{2}$ También añadirá que sus "romances miran a lo elemental humano", ${ }^{3}$ es decir, que parten de la vida del hombre. Una nota autobiográfica de Antonio Machado recuerda el lugar de su nacimiento; "Nací en Sevilla una noche de junio de 1875 en el célebre palacio de Dueñas, sito en la calle del mismo nombre", ${ }^{4}$ texto que se corresponde con el soneto "Esta luz de Sevilla" en el cual el poeta evoca la figura de su padre:

Esta luz de Sevilla ... Es el palacio donde nací, con su rumor de fuente, mi padre, en su despacho. - La alta fuente, la breve mosca, y el bigote lacio. (Nuevas canciones, CLXV, IV)

De su infancia sevillana Machado dará constancia en el poema "Retrato" de Campos de Castilla: el patio y el huerto, la fuente y el limonero:

Mi infancia son recuerdos de un patio de Sevilla y un huerto claro donde madura el limonero.

paisaje de Andalucía que persistirá, no importa los estragos del tiempo y del olvido. De las Poesías de la guerra civil (1936-1939) son los bellísimos endecasílabos del soneto LXIII-VI "Otra vez el ayer. Tras la persiana":

Mi Sevilla infantil ¡tan sevillana!

¡cuál muerde el tiempo tu memoria en vano!

ADOLESCENCIA Y JUVENTUD: MADRID 1883-1907

En nota autobiográfica Machado recuerda: "Mi adolescencia y mi juventud son madrileñas". ${ }^{5}$ Machado estudia en la Institución Libre de Enseñanza que, entre otras muchas buenas cosas, propiciaba entre sus alumnos el amor a la naturaleza por las frecuentes excursiones que organizaba la Institución a la sierra de Guadarrama y a las ciudades y pueblos próximos a Madrid. La preocupación por el paisaje - que Machado comparte con los miembros de la generación del

\footnotetext{
${ }^{2}$ Ibid., p. 19.

${ }^{3}$ lbid.

${ }^{4}$ Ibid., p. 15.

${ }^{s}$ Ibid.
} 
noventa y ocho- se reflejará en la obra del poeta, en la geografía de España, tomada no sólo como rasgo generacional sino también como honda vibración del espíritu. El paisaje se hace presente lleno de simbolismo: la fuente y la tarde, el agua y las estaciones, los sueños:
El limonero lánguido suspende
una pálida rama polvorienta
sobre el encanto de la fuente limpia,
y allá en el fondo sueñan
los frutos de oro...
(Soledades, VII)

"frutos de oro", doradas ilusiones que escaparán cuando sè intente apresarlas. La serie de Galerías ( = las del alma) contiene quizá los poemas más hondos de Machado: el viento, los sueños y la primavera hablan con el poeta y le reprochan la "juventud nunca vivida":
Bajo ese almendro florido, todo cargado de flor -recordé- yo he maldecido mi juventud sin amor.
Hoy, en la mitad de la vida, me he parado a meditar... ¡Juventud nunca vivida, quién te volviera a soñar! (LXXXV)

Durante estos años Machado vivió sin encontrar el amor o esperando al amor que no llegaba. Lamentación, pesar y nostalgia reflejan los poemas de esta época.

\section{LA MADUREZ Y EL AMOR, SORIA (1907-1912)}

La ciudad del Duero, la Soria cantada por Bécquer, significó para Antonio Machado el final de la juventud y la entrada en la madurez y el amor. El poeta escribe: "En 1907 obtuve cátedra de Lengua francesa, que profesé durante cinco años en Soria. Allí me casé; allí murió mi esposa, cuyo recuerdo me acompaña siempre". ${ }^{6}$ En el prólogo de Campos de Castilla, Machado comenta: "Cinco 
años en la tierra de Soria, hoy para mí sagrada -allí me casé, allí perdí a mi esposa, a quien adoraba-, orientaron mis ojos y mi corazón hacia lo esencial castellano". ${ }^{7}$ La geografía de Soria fue realmente sugerente para Machado, a juzgar por los bellos poemas que le inspiró la naturaleza y el paisaje:

He vuelto a ver los álamos dorados, álamos del camino en la ribera del Duero, entre san Polo y san Saturio, tras las murallas viejas de Soria - barbacana hacia Aragón, en castellana tierra-. ("Campos, de Soria" CXIII, $\mathrm{V}$ en Campos de Castilla)

El paisaje de Soria siempre acompañó a Machado. En Nuevas canciones (1917-1930), Machado recuerda a "Soria de montes azules/ y de yermos de violeta,/ ¡cuántas veces te he soñado/ en esta florida vega" ("Canciones de las tierras altas", CLVIII). Y el lema del escudo de Soria Machado lo integrará a los primeros versos del poema CXIII, VI: “iSoria fría, Soria pura,/ cabeza de Extremadura".

En Soria, Machado encuentra el amor "mas recibí la flecha que me asignó Cupido/ y amé cuanto ellas puedan tener de hospitalario" ("Retrato", XCVII, Campos de Castilla). Feliz noviazgo con Leonor Izquierdo, adolescente de quince años, Antonio contaba treinta y cuatro: "En Santo Domingo,/ la misa mayor./ Aunque me decían/ hereje y masón,/ rezando contigo,/ ¡cuánta devoción!” (Nuevas canciones, CLIX, XII). El día cuatro de mayo de 1912, el poeta escribe "A un olmo seco" y canta el milagro del viejo olmo "hendido por el rayo/ y en su mitad podrido", al que la primavera hace retonar "algunas hojas verdes". Antonio Machado clama por otro milagro de la primavera: la curación de Leonor:

\section{Mi corazón espera}

también, hacia la luz y hacia la vida, otro milagro de la primavera.

(Campos de Castilla, CXV)

No ocurre el milagro, Leonor muere el primero de agosto de 1912. Machado expresará su dolor en patética estrofa, hondo grito de su alma: 
Señor, ya me arrancaste lo que yo más quería.

Oye otra vez, Dios mío, mi corazón clamar.

Tu voluntad se hizo, Señor, contra la mía.

Señor, ya estamos solos mi corazón y el mar.

(Ibid., CXIX)

PLENA MADUREZ, LA INQUIETUD FILOSÓFICA, BAEZA, 1912-1919

Después de la muerte de Leonor, Antonio Machado abandona Soria. Su nuevo destino es Baeza, provincia de Jaén, Andalucía. Reencuentro con el paisaje natal al que tratará de cantar como antes, a la tierra soriana:

Hoy, a tu sombra, quiero

ver estos campos de mi Andalucía, como a la vera ayer del Alto Duero

la hermosa tierra de encinar veía.

(Nuevas canciones, CLIII, II)

Machado subraya el carácter de Baeza "entre andaluz y manchego" (Campos de Castilla, CXXVIII). Aquí pasará siete años en la llamada Salamanca andaluza. El poeta hace frecuentes paseos desde Baeza a Úbeda, camino en el que puede contemplar el paisaje andaluz: "Campo, campo, campo./ Entre los olivos,/ los cortijos blancos" (Ibid., CLIV). En Apuntes, Machado canta:

Desde mi ventana, ¡campo de Baeza, a la luna clara!

(Ibid., CLIV, I).

Durante los años de Baeza, Machado estudia filosofía por libre en la Universidad Central de Madrid. El amor deja paso al amor por la filosofía. Dámaso Alonso ha sostenido la tesis de que Machado, "aprendiz de filósofo", perjudicó al poeta Antonio Machado. ${ }^{8}$ Sea como fuere, la prosa y el verso meditativos y sentenciosos son exacta expresión del estado de ánimo del poeta en el ambiente de Baeza. En una carta escrita a Unamuno en 1913, Machado comenta: "Aquí

8 “Antonio Machado" en Cuatro poetas españoles, de Dámaso Alonso. Madrid: Gredos, 1962 (BRH, 3). Dámaso Alonso llama a Machado "aprendiz de filósofo" (p. 155). Añade en la p. 176: "Por otra parte, debo decir que el encuentro con la filosofía, me expresaré mejor, con la historia de la filosofía reciente, fue fatal para su poesía [...] Machado cambió por cobre filosófico buena parte de su oro poético de ayer." 
no se puede hacer nada - lo digo con tristeza porque, al fin, son de mi familiatienen el alma absolutamente impermeable". Machado se entrega a la filosofía con ardor ("Si algo estudié con ahínco fue más de filosofía que de amena literatura" $\left.{ }^{9}\right)$. En esta época Machado escribe una serie de breves poemas filosóficos, concisos, irónico nace el poeta filósofo que canta sus meditaciones en torno a la filosofía: "¿Dices que nada se pierde?/ Si esta copa de cristal/ se me rompe, nunca en ella beberé, nunca jamás" (Proverbios y cantares, Campos de Castilla, CXXXVI, XLII). Machado, tan sensible al paisaje, señala su posible añoranza del campo andaluz en caso de que no pudiera contemplarlo:

¡Campo de Baeza, soñaré contigo cuando no te vea! (Apuntes, Ibid., CLIV, IV)

\section{A LA MITAD DEL CAMINO, "AMOR INTEMPESTIVO", SEGOVIA-MADRID, 1919-1931}

"Desde 1919 paso la mitad de mi tiempo en Segovia y en Madrid la otra mitad, aproximadamente". ${ }^{10}$ Antonio Machado se incorpora al Instituto de Segovia: "En Segovia una tarde de paseo/ por la alameda que el Eresma baña" (Cancionero apócrifo, CLXXXI). En Segovia será donde el poeta recibe el dardo de Cupido y la llegada de un nuevo amor después de dieciséis años de viudez - Machado tiene cincuenta y tres años-. En 1928 el poeta conoce a Guiomar. En un bello soneto que comienza con el conocido verso de Dante ("A la mitad del camino de la vida"), Machado acusa haber recibido el flechazo de "un amor intempestivo":

Nel mezzo del cammin pasóme el pecho

la flecha de un amor intempestivo.

Que tuvo en el camino largo acecho mostróme en lo certero el rayo vivo. (Ibid., CLXVII)

En septiembre de 1929, Machado publica las primeras Canciones a Guiomar en la Revista de Occidente: "En un jardín te he soñado,/ alto, Guiomar, sobre el

\footnotetext{
${ }^{9}$ Antonio Machado. Proyecto de discurso de ingreso en la Academia de la Lengua. En Antonio Machado, ed. De José Luis Cano, Madrid: Bruguera, 1984, p. 480, (LA, 914).

${ }^{10}$ Antonio Machado. Poesías completas, Op. cit., p.16.
} 
río,/ jardín de un tiempo cerrado/ con verjas de hierro frío" (Ibid., CLXXIII, II). El entusiasmo del poeta se trasluce en la declaración exaltada:
Por ti la mar ensaya olas y espumas, y el iris, sobre el monte, otros colores, y el faisán de la aurora canto y plumas, y el búho de Minerva ojos mayores, Por ti, ¡oh Guiomar!...
(Ibid.)

Antonio Machado amó intensamente a Guiomar: "Porque tú eres, no lo dudes, el gran amor de mi vida". ${ }^{11}$ El poeta se siente encadenado: "De qué sustancia invisible es la cadena que me echaste al cuello". ${ }^{12}$ En sus cartas Machado llama a Guiomar "mi diosa", "diosa mía", "mi reina", "mi gloria", ${ }^{13}$ y firma con un posesivo: "tu Antonio", "tu poeta". ${ }^{14}$ Estos y parecidos términos en los poemas que dedica a Guiomar:
Tu poeta
piensa en ti. La lejanía
es de limón y violeta,
verde el campo todavía.
(Ibid., III)

¿Por qué llamó Machado a su amada, Guiomar? José Luis Cano cree posible esta preferencia dado que la esposa de Jorge Manrique se llamaba así, o la infanta Guiomar de la que habla el Romancero. ${ }^{15}$ Pero, ¿quién era Guiomar? Un soneto que Machado dedica a su diosa con motivo del día de su santo - y que le envía junto con un libro de poesía de Dante- rebela la identidad del nombre. Guiomar es Pilar de Valderrama:

\section{Perdón, Madonna del Pilar, si llego al par que nuestro amado florentino,}

\footnotetext{
${ }^{11}$ Citado por José Luis Cano en "Un amor tardío de Antonio Machado: Guiomar" en Antonio Machado, ed. De Ricardo Gullón y Allen W. Phillips, Madrid: Taurus, 1973, p. 110 (Taurus, 63).

${ }^{12}$ Citado por José Luis Cano en "Un amor tardío de Antonio Machado: Guiomar", Op. cit., p. 106 y 107.

${ }_{13}$ En los poemas y en las cartas a Guiomar, Machado usa las mismas expresiones amorosas, prueba de autenticidad. Véase: José María Moreiro, “Guiomar, un amor imposible de Antonio Machado". Siete cartas de don Antonio. Madrid: Espasa-Calpe, 1982, pp. 159-220 (Austral, 97).

${ }^{14}$ Ibid.

${ }^{15}$ José Luis Cano. "Un amor tardío de Antonio Machado: Guiomar”, Op. cit., p. 106 y 107.
} 
con una mata de serrano espliego, con una rosa de silvestre espino.

¿Qué otra flor para ti de tu poeta si no es la flor de su melancolía? (Otras canciones a Guiomar, CLXXV, I)

Antonio Machado guardó celosamente el secreto de esta relación amorosa con Pilar Valderrama porque su diosa era una señora casada y no quería comprometerla. Según José Luis Cano, Machado habló en alguna ocasión de "la barrera que ha puesto la suerte entre nosotros", ${ }^{16}$ y que no podía ser otra que el matrimonio de Guiomar. Pilar de Valderrama, poeta y autora del libro Esencias, fue una mujer real, inteligente y comprensiva. En 1981 se publica el libro de memorias de Pilar de Valderrama, Sí; soy Guiomar, ${ }^{17}$ con las treinta y seis cartas íntegras de Antonio Machado que Pilar conservaba de su poeta:

¡Y en la tersa arena, cerca de la mar, tu carne rosa y morena, súbitamente, Guiomar! (Cancionero apócrifo, CLXXIV)

ÚlTIMOS AÑOS: "LA TIERRA. SE DESGARRA", MADRID, VALENCIA, 1936-1939

De las ciudades y paisajes de los años de la guerra civil española, Antonio Machado ha dejado constancia en bellos versos. El poeta canta a la ciudad de Madrid, desgarrada pero sonriente, el día siete de noviembre de 1936:

¡Madrid, Madrid!, ¡qué bien tu nombre suena, rompeolas de todas las Españas!, la tierra se desgarra, el cielo truena, tú sonríes con plomo en las entrañas. (Poesías de la guerra, (1936-39) I)

Machado recuerda la muerte de Federico García Lorca en el bello poema "El crimen fue en Granada" y no olvida mencionar a la Alhambra y a las fuentes árabes que eternamente llorarán la muerte de Federico:

${ }^{17}$ Pilar de Valderrama, Si, soy Guiomar, Barcelona, Plaza y Janes, 1981. 


\author{
Labrad, amigos, \\ de piedra y sueño, en el Alhambra, \\ un túmulo al poeta, \\ sobre una fuente donde llore el agua, \\ y eternamente diga: \\ el crimen fue en Granada, ;en su Granada! \\ (Ibid., LXV, III)
}

"Amanecer en Valencia" es un soneto publicado en 1938 en la Hora de España. El subtítulo "Desde una torre" anticipa ya la visión panorámica de espléndidas imágenes y colorido que canta el poeta:

Valencia de fecundas primaveras, de floridas almunias y arrozales, feliz quiero cantarte, como eras, domando a un ancho río en tus canales, al dios marino con tus albuferas, al centauro de amor con tus rosales. (Ibid., LXIII, III)

En Rocafort, pequeño pueblecito a ocho kilómetros de Valencia, Machado escribe "Meditación" (S. LXIV), publicado en 1938, fina estampa, evocación de la caída de la noche sobre Valencia, mientras el rumor de la guerra se duerme a lo lejos:

¡Como parece dormida la guerra, de mar a mar, mientras Valencia florida se bebe el Guadalaviar! Valencia de finas torres y suaves noches, Valencia, ¡estaré contigo, cuando mirarte no pueda, donde crece la arena del campo y se aleja la mar violeta! (Ibid., LXIV)

El poema "Voz de España” refleja una vez más al Machado de la generación del noventa y ocho por su evocación de toda la tierra española que el poeta quiere 
abarcar de un solo trazo: las "vastas liras de piedra y sol" que recuerdan la España de otro poema ("España mía,/ - ancha lira, hacia el mar, entre dos mares-," S LXIII, VII), visión panorámica y globalizadora: “por estas tierras/ por sus llanuras/ por sus campos/ de monte a monte y río a río/ de mar a mar":

Por estas tierras altas erizadas de sierras, vasta liras de piedra y sol, por sus llanuras pardas y por sus campos verdes.

Sus ríos hondos, sus marinas claras, bajo la negra encina y el áureo limonero, junto al clavel y la retama, de monte a monte y río a río ¿oyes la voz de España? (Ibid., LXXI)

En Rocafort, 1938, Antonio Machado escribe un soneto conmovedor a Guiomar, pleno de nostalgia por el amor tardío que nunca llegó a florecer. La guerra hirió de muerte la relación amorosa entre Machado y Guiomar ("La guerra dio al amor el tajo fuerte"). Ambos contemplaban mares diferentes. Machado, el Mediterráneo; Guiomar, el Atlántico ("que Camoens cantara"). Él en Valencia; ella en Portugal o Galicia (de ahí la alusión "a un finisterre"). La obsesiva presencia de Guiomar se revela en la repetición de la palabra mar, seis veces en los cinco primeros versos del soneto. El amor no dará ya frutos de amor tardío, será imposible ya la flor, todo sucumbe ante el corte frío del hachazo fratricida. Duele al poeta el recuerdo de su diosa, la angustia de la muerte, y la muerte de su amor por el atroz tajo de la guerra:

De mar a mar entre los dos la guerra, más honda que el mar. En mi parterre mira a la mar que el horizonte cierra. Tú asomada, Guiomar, a un finisterre, miras hacia otro mar, la mar de España que Camoens cantara, tenebrosa.

Acaso a ti mi ausencia te acompaña, a mí me duele tu recuerdo, diosa.

La guerra dio al amor el tajo fuerte. $Y$ es la total angustia de la muerte, con la sombra infecunda de la llama 
y la soñada miel de amor tardío, y la flor imposible de la rama que ha sentido del hacha el corte frío. (Ibid., LXIII, V)

\section{"EL ÚlTIMO VIAJE", COLLIOURE, 1939}

En agosto de 1937, en Valencia, en una entrevista que le hiciera a Antonio Machado Pascual Pla y Beltrán, el poeta había vaticinado que separarse de España, abandonar su amada tierra española, vivir en suelo extranjero, para él equivaldría a morir:

cuando pienso en un posible destierro, en una tierra que no sea esta atormentada tierra española, mi corazón se llena de pesadumbre. Tengo la certeza de que el extranjero significaría para mí la muerte. ${ }^{18}$

Esta premonición se unía a la de antaño, cuando habló en el poema "Retrato" de Campos de Castilla, "del último viaje", el sin retorno, y en condiciones del máximo despojamiento. Efectivamente, Machado llegó al Pirineo, camino del exilio, desprovisto de equipaje. El bellísimo cuarteto alejandrino de 1912 alcanzaba plena vigencia en aquel 27 de enero de 1939 en el que Antonio cruzaba la frontera francesa:

Y cuando llegue el día del último viaje, y esté al partir la nave que nunca ha de tornar, me encontraréis a bordo ligero de equipaje, casi desnudo, como los hijos de la mar.

(Campos de Castilla, XCVII)

En uno de sus primeros libros, Del camino, 1903, Antonio Machado había predicho el inevitable encuentro con la muerte:

Al borde del sendero un día nos sentamos.

Ya nuestra vida es tiempo, y nuestra sola cuita

son las desesperantes posturas que tomamos

para aguardar... Mas Ella no faltará a la cita. (XXXV)

${ }^{18}$ Pascual Pla y Beltrán. "Mi entrevista con Antonio Machado" en Antonio Machado, ed. De Ricardo Gullón y Allen W. Phillips, Op. cit., p. 46. 
La cita del poeta con la muerte fue el 22 de febrero de 1939. Antonio Machado, una de las voces más puras de la poesía española del siglo xx, moría en Collioure, pueblecito cercano de la frontera hispano-francesa. Las vivencias del paisaje andaluz que acompañaron a Machado durante toda su vida, se sintetizarán en el último verso del poeta, encontrado después de su muerte en el bolsillo de su gabán. ${ }^{19}$ Dice así:

Estos días azules y este sol de la infancia

Último y emocionado recuerdo: nostalgia de los días claros y de sol de Sevilla de los primeros años del gran poeta sevillano y español de la generación del noventa y ocho: Antonio Machado. 